University of Nebraska - Lincoln

DigitalCommons@University of Nebraska - Lincoln

1987

\title{
Sorption of Binary Mixtures of Aromatic Nitrogen Heterocyclic Compounds on Subsurface Materials
}

John M. Zachara

Pacific Northwest National Laboratory, john.zachara@pnl.gov

Calvin C. Ainsworth

Pacific Northwest National Laboratory

Christina E. Cowan

Pacific Northwest National Laboratory

Berta L. Thomas

Pacific Northwest National Laboratory

Follow this and additional works at: https://digitalcommons.unl.edu/usdoepub

Part of the Bioresource and Agricultural Engineering Commons

Zachara, John M.; Ainsworth, Calvin C.; Cowan, Christina E.; and Thomas, Berta L., "Sorption of Binary Mixtures of Aromatic Nitrogen Heterocyclic Compounds on Subsurface Materials" (1987). US Department of Energy Publications. 205.

https://digitalcommons.unl.edu/usdoepub/205

This Article is brought to you for free and open access by the U.S. Department of Energy at DigitalCommons@University of Nebraska - Lincoln. It has been accepted for inclusion in US Department of Energy Publications by an authorized administrator of DigitalCommons@University of Nebraska - Lincoln. 


\title{
Sorption of Binary Mixtures of Aromatic Nitrogen Heterocyclic Compounds on Subsurface Materials
}

\author{
John M. Zachara, ${ }^{*}$ Calvin C. Ainsworth, Christina E. Cowan, and Berta L. Thomas
}

Pacific Northwest Laboratory, Richland, Washington 99352

\begin{abstract}
- Single and binary solute sorption of pyridine, quinoline, and acridine has been investigated on two low organic carbon subsurface materials with similar properties but different equilibrium $\mathrm{pH}$ when saturated with water. Single solute sorption for all compounds is higher in the acidic soil as compared to the basic soil, reflecting stronger sorption of the protonated organic cations. The protonated species exhibit high selectivity for the exchange complex at low aqueous concentration with selectivity increasing with ring number. Binary sorption experiments with quinoline/pyridine and quinoline/acridine demonstrate that competitive sorption occurs between compounds in the acidic subsoil where the protonated compound species predominate in solution. In contrast, competition is minimal in the basic subsoil when the compounds are neutral. The competition between compounds is consistent with their measured single solute sorption and suggests mass action on a common set of high-affinity surface sites. A simplified model based on ideal adsorbed solution theory (IAS) is used to provide simulations of binary solute sorption that are in good qualitative agreement with experimental results. It is suggested that competition between ionized solutes may significantly influence transport of organic mixtures when the groundwater $\mathrm{pH}$ is near the $\mathrm{p} K_{\mathrm{a}}$ of the compounds.
\end{abstract}

\section{Introduction}

Organic contaminants are often released from waste materials to subsurface environments as a solute mixture. Accurately predicting the solute migration requires information on the sorption characteristics of the individual compounds as modified by other constituents in the mixture. Interactions between organic solutes in dilute mixtures $\left(<10^{-4} \mathrm{M}\right)$ may conceivably occur in the interfacial region of solid adsorbents and via molecular association in the aqueous phase. Information on these interactions is limited, and accurate predictions of migration of solute mixtures are not possible at present. In this paper the multisolute sorption behavior of ionizable aromatic organic compounds is investigated to determine if competitive solute-sorbent interactions occur.

Evidence suggests that interactions of cosorbing solutes at the solid/liquid interface via competitive mass action and electrostatic effects are significant in the adsorption of trace inorganic ions by soil, subsurface materials, and mineral adsorbents $(1-4)$. Comparable information is scant for organic molecules. Competitive adsorption has been observed for fully ionized organic cations (paraquat, diquat) on layer lattice silicates $(5,6)$ and for chlorinated phenols on soils when solution $\mathrm{pH}$ is near the compound $\mathrm{p} K_{\mathrm{a}}(7)$. In contrast, preliminary evidence suggests that nonionic organic compounds may sorb independently on soil from mixtures (8). This evidence is insufficient to predict when competitive sorption may occur in soil or in lower organic carbon substrates from subsurface or aquifer environments.

Multisolute adsorption from dilute solution has been investigated extensively on activated carbon with hydrophobic/neutral (9) and ionizable (10-13) compounds. Competitive interactions are commonly observed and as- cribed to multiple surface equilibria on heterogeneous surface sites that vary in their affinity for the reacting solutes. Multisolute adsorption behavior has been described by extensions of single solute isotherm equations $(14,15,11)$, simulated by thermodynamic (16) and molecular reaction models (17), and evaluated with the solvophobic interaction approach (18). Activated carbon differs in many ways from unconsolidated earthen materials, but the results and theoretical development with activated carbon are relevant to subsurface materials that commonly exhibit heterogeneity in both surface sites and hydrophobicity of exposed surfaces.

The objectives of this work are to document possible competitive sorption occurring in binary mixtures of hydrophobic ionizable compounds (HIOC) on subsurface materials, to determine chemical conditions that promote competition, and to establish the magnitude of competitive interactions. A series of ionizable $\mathrm{N}$-containing aromatic compounds-pyridine, quinoline, and acridine-are used with two subsurface materials of different equilibrium $\mathrm{pH}$ in water to evaluate competitive sorption in batch equilibrium experiments. The nitrogen heterocycles (NHC) are useful probes of competitive interactions because they may exist in either the neutral or cationic form over the typical range in groundwater $\mathrm{pH}$ and are important from an environmental health perspective (19).

\section{Experimental Section}

Subsoils. Earlier work (20) has demonstrated that the sorption of quinoline on suspensions of subsurface materials is governed by the equilibrium $\mathrm{pH}$, which determines the ionization fraction $\left[Q=\left[\mathrm{BH}^{+}\right] /\left([\mathrm{B}]+\left[\mathrm{BH}^{+}\right]\right)\right]$and extent of ion exchange. Two vadose zone materials of low organic carbon (Loring, Anvil Points soils) were selected as experimental adsorbents to probe competitive interactions when the compounds were ionized and neutral. These materials, herein called subsoils, differ primarily in their equilibrium $\mathrm{pH}$ with water. The Loring subsoil is a lower B horizon (Bx, Typic Fragiudult) of loessial origin (21) that was obtained from the Ohio River Basin (Kentucky). The Anvil Points subsoil is a colluvial mixture of kerogeneous dolomite and gypsferous claystone taken from approximately $2 \mathrm{~m}$ below the Nihill soil series (Torrifluvent) in western Colorado. A zone of saturated groundwater movement occurs $2 \mathrm{~m}$ below the sampling depth.

The two subsoils differ by approximately 3 units in $\mathrm{pH}$ and suriace coating mineralogy, reflecting their respective weathering environments, but are similar in other gross properties (Table I). With the exception of the mineralogic analyses, methodologies for these characterizations have been presented elsewhere (20). Mineralogic analyses were performed on the $<2.0-\mu \mathrm{m}$ fraction isolated by sedimentation following sonification $(15 \mathrm{~min}$ at $300 \mathrm{~W})$ of the whole subsoil. Oriented slides saturated with $\mathrm{K}^{+}, \mathrm{Mg}^{2+}$, ethylene glycol, and dimethyl sulfoxide $\left(\mathrm{Me}_{2} \mathrm{SO}\right)$ were made from dithionite-citrate-bicarbonate-extracted and unextracted subsamples of the Loring clay fraction and sodium acetate extracted and unextracted subsamples of the Anvil Points clay fraction. These slides were subjected to X-ray diffraction analysis with $\mathrm{Ni}$-filtered $\mathrm{Cu} \mathrm{K} \alpha$ ra- 


\begin{tabular}{|c|c|c|c|c|c|c|c|c|c|c|c|c|}
\hline \multirow[b]{2}{*}{ subsoil } & \multicolumn{2}{|c|}{ organic $\mathrm{C}$} & \multicolumn{3}{|c|}{$\begin{array}{c}\text { particle } \\
\text { distribution }\end{array}$} & \multicolumn{2}{|c|}{ surface area } & \multirow{2}{*}{$\begin{array}{l}\text { CEC, } \\
\text { mequiv/ } \\
100 \mathrm{~g}^{a}\end{array}$} & \multirow[b]{2}{*}{$\underset{\left(\mathrm{H}_{2} \mathrm{O}\right)}{\mathrm{pH}}$} & \multirow{2}{*}{$\begin{array}{c}\mathrm{pH} \\
(0.01 \mathrm{M} \\
\left.\mathrm{CaCl}_{2}\right)\end{array}$} & \multirow[b]{2}{*}{$\mathrm{cm} /$} & \multirow[b]{2}{*}{$\begin{array}{c}\text { clay } \\
\text { mineralogyc }\end{array}$} \\
\hline & $\begin{array}{c}\text { total, } \\
\%\end{array}$ & $\begin{array}{c}\text { extractable } \\
\%\end{array}$ & $\begin{array}{l}\text { sand, } \\
\%\end{array}$ & $\begin{array}{l}\text { silt, } \\
\%\end{array}$ & $\begin{array}{c}\text { clay, } \\
\%\end{array}$ & $\begin{array}{l}\mathrm{N}_{2}, \\
\mathrm{~m}^{2} / \mathrm{g}\end{array}$ & $\begin{array}{c}\text { EGME, } \\
\mathrm{m}^{2} / \mathrm{g}\end{array}$ & & & & & \\
\hline Loring & 0.24 & 0.19 & $\begin{array}{r}2 \\
98\end{array}$ & 70 & 28 & 30.5 & 66.9 & 8.4 & 4,85 & 4.18 & 117 & $\mathrm{~V}, \mathrm{M}, \mathrm{Mi}, \mathrm{G}$ \\
\hline
\end{tabular}

diation $\left(2-50^{\circ}\right.$ in $2 \theta$; tube current $35 \mathrm{kV}, 20 \mathrm{~mA}$; scanning speed $2^{\circ}$ in $2 \theta / \mathrm{min}$ ).

Organic Compounds and Analysis. Unlabeled pyridine (99\% purity, Aldrich), quinoline (99\% purity, Aldrich), and acridine (99\% purity, Aldrich) were used without purification. Radiolabeled $\left({ }^{14} \mathrm{C}\right.$-uniform ring label) quinoline was synthesized by Pathfinder Laboratories and further purified by liquid chromatography (Waters Associates, C-18 column, $25 \mathrm{~cm} \times 3.9 \mathrm{~mm}$ ) with a $40 \%$ acetonitrile $/ 60 \%$ citrate buffer. The peak corresponding to quinoline was collected, partitioned into hexane, and back-extracted in $0.05 \mathrm{~N} \mathrm{HCl}$. The radiochemical purity was greater than $99 \%$, and specific activity was 9.72 $\mathrm{mCi} / \mu \mathrm{mol}$.

Unlabeled quinoline, pyridine, and acridine were quantified by high-performance liquid chromatography (HPLC) with a $25-\mathrm{cm}$ C-18 column and a methanol/acetate buffer mobile phase. ${ }^{14} \mathrm{C}$-Labeled quinoline was determined by liquid scintillation counting, with frequent HPLC analysis to substantiate tracer integrity. Acridine standards for HPLC analysis and sorption experiments were prepared daily because of acridine's limited solubility and lability. Standards were prepared by dissolving the solid compound in $10 \mathrm{~mL}$ of $1 \mathrm{~N} \mathrm{HCl}$ with sonification, diluting to $200 \mathrm{~mL}$ with deionized $\mathrm{H}_{2} \mathrm{O}$, and adjusting to $\mathrm{pH} 6$ with $\mathrm{Ca}(\mathrm{OH})_{2}$.

Sorption Experiments. Single solute isotherms for quinoline were determined over a large concentration range, and all binary solute experiments were performed with quinoline as a reference compound to judge the presence or absence of competition.

(A) Single Solute Sorption. Batch sorption experiments at $25^{\circ} \mathrm{C}$ were carried out in $25-\mathrm{mL}$ Corex centrifuge tubes at a 1:5 $(2 \mathrm{~g} / 10 \mathrm{~mL})$ solid-to-solution ratio for quinoline and pyridine and a $1: 100(0.1 \mathrm{~g} / 10 \mathrm{~mL})$ ratio for quinoline and acridine. A nitrogen atmosphere and sparged solutions were used to suppress aerobic microbiological degradation (22). The subsoils were preequilibrated with $0.01 \mathrm{M} \mathrm{CaCl}_{2}$ for $4 \mathrm{~h}$ before adding the organic solute. Varying quantities of unlabeled quinoline were added to the subsoil suspensions along with a fixed quantity of ${ }^{14} \mathrm{C}$-labeled quinoline (approximately 50000 $\mathrm{dpm}$ ) to yield a concentration range of $2.6 \times 10^{-7}$ to $1.0 \times$ $10^{-4} \mathrm{M}$. Compound standards were adjusted to the approximate $\mathrm{pH}$ of the subsoil before addition. Each concentration was run in duplicate. A similar procedure, minus the radiolabel, was followed for pyridine and acridine with initial concentration ranges of $2.6 \times 10^{-6}$ to 1.2 $\times 10^{-3} \mathrm{M}$ and $3.8 \times 10^{-7}$ to $2.3 \times 10^{-3} \mathrm{M}$, respectively. The lower concentration limit of the pyridine and acridine isotherms was governed by the sensitivity and detection limit of the HPLC analyses. Following $24 \mathrm{~h}$ of agitation in a controlled-environment shaker, the tubes were centrifuged at $7500 \mathrm{~g}$ for $20 \mathrm{~min}$, and sorbate concentrations in the supernatant were analyzed.

A previous time course study (20) had demonstrated that quinoline sorption equilibrium in subsoil was attained within $4 \mathrm{~h}$. A 24-h time period was used in this study to

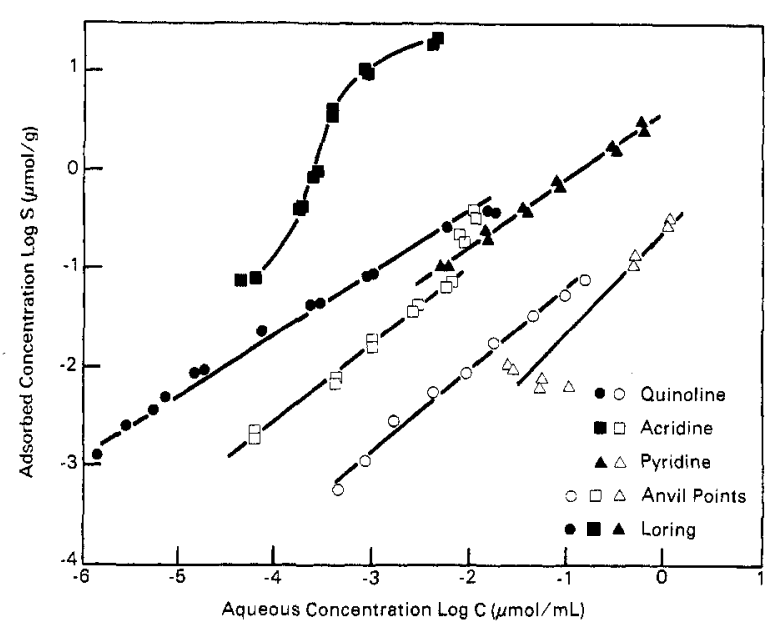

Figure 1. Single solute sorption of pyridine, quinoline, and acridine on acid and basic subsoils. Solid-to-solution ratio is $1: 100$ for acridine in Loring subsoll and 1:5 for all other combinations.

assure that steady-state conditions were attained for all three NHC in the two subsoils. The amount adsorbed was calculated by using the difference between initial and final sorbate concentrations. High-performance liquid chromatography analysis gave no evidence of sorbate degradation over the equilibration period.

(B) Multisolute Sorption. Multiple solute experiments were performed with binary solute mixtures of quinoline/pyridine and quinoline/acridine. Quinoline isotherms were run in both subsoils (1:5 solid-to-solution ratio) with pyridine cosolute concentrations of $1.26 \times 10^{-5}$, $6.32 \times 10^{-5}$, and $1.26 \times 10^{-4} \mathrm{M}$. Quinoline isotherms (1:5 ratio) were run with acridine cosolute concentrations of $3.9 \times 10^{-6}, 1.9 \times 10^{-5}$, and $3.8 \times 10^{-5} \mathrm{M}$ in the Loring subsoil and $2.50 \times 10^{-6}$ and $1.25 \times 10^{-4} \mathrm{M}$ in the Anvil Points subsoil. Because of the high sorption of acridine, an additional set of isotherms with acridine at $2.50 \times 10^{-6}, 1.29$ $\times 10^{-5}$, and $1.29 \times 10^{-4} \mathrm{M}$ was run in the Loring subsoil at a low solid-to-solution ratio $(1: 100)$ to minimize the percent change in sorbate concentrations during sorption.

The adsorption procedure described previously for single solutes was followed identically for the binary solute studies. The reactive cosolute was added immediately following the quinoline, with both spiking solutions adjusted to the approximate $\mathrm{pH}$ of the subsoils. Following the 24-h equilibration period and phase separation, quinoline was quantified by liquid scintillation counting with periodic HPLC analysis for corroboration. High-performance liquid chromatography analysis for pyridine and acridine was performed when competition with quinoline was observed.

\section{Results and Discussion}

Single Solute Experiments. The sorption of all three NHC in the two subsoils produced nonlinear isotherms that were partially linearized on a $\log -\log$ basis (Figure 1 ). 


\begin{tabular}{llccc}
\hline \multicolumn{5}{l}{ Table II. Freundlich Adsorption Parameters } \\
\multirow{4}{*}{ subsoil } & \multicolumn{1}{c}{ compd } & $\begin{array}{c}K_{\mathbf{F}}, \mu \mathrm{mol}^{1-N} \\
\mathrm{~g}^{-1} \mathrm{~mL}^{N}\end{array}$ & $N$ & $r^{2}$ \\
Loring & pyridine & 5.56 & 0.720 & 0.988 \\
& quinoline $(1: 5)$ & 5.17 & 0.580 & 0.939 \\
& quinoline $(1: 100)$ & 3.14 & 0.567 & 0.985 \\
Anvil Points & acridine & 74989 & 1.31 & 0.886 \\
& pyridine & 0.231 & 1.04 & 0.827 \\
& quinoline (1:5) & 0.480 & 0.868 & 0.997 \\
& acridine & 23.5 & 1.02 & 0.950 \\
\hline
\end{tabular}

Table III. Nitrogen-Containing Aromatic Compounds

\begin{tabular}{|c|c|c|c|c|}
\hline compd & structure & $\begin{array}{l}\text { solubility, } \\
\mu \mathrm{g} / \mathrm{mL}\end{array}$ & $\begin{array}{l}\text { ionization, }^{a} \\
\mathrm{BH}^{+} \underset{\left(\mathrm{p} K_{\mathrm{a}}\right)}{\rightleftarrows \mathrm{B}}+\mathrm{H}^{+}\end{array}$ & $K_{\mathrm{o} / \mathbf{w}^{b}}^{b}$ \\
\hline pyridine & & miscible & 5.23 & $\sim 10$ \\
\hline quinoline & & 6000 & 4.92 & $\sim 110$ \\
\hline acridine & & $\sim 38.4$ & 5.68 & 2512 \\
\hline
\end{tabular}

${ }^{a}$ Perrin, D. D.; Dempey, B.; Sergeant, E. P. In $p K$ Prediction for Organic Acids and Bases; University Printing House: Cambridge, $1981 ; \mathrm{p} 4 .{ }^{b} K_{\mathrm{o} / \mathrm{w}}$ is octanol-water partition coefficient.

In partial agreement with the findings of Banwart et al. (23) and Means et al. (24), linear sorption was observed for the most hydrophobic compound in the series (acridine) over a limited concentration range in the basic subsoil. The isotherms gave poor fit to the Langmuir equation but were adequately described by the Freundlich equation ( $S$ $=K_{\mathrm{F}} C_{\mathrm{e}}{ }^{N}$, Table II). Within each subsoil, sorption increases from pyridine to quinoline to acridine-an order reverse to their respective aqueous solubilities and in agreement with octanol-water partition coefficients (Table III). Similar relationships between compound solubility and sorption have been observed for acridine and sparingly soluble NHC in soil and sediment (23), amino-substituted PAH (24), and other hydrophobic compounds $(25,26)$ in which organic matter is considered the dominant adsorbent.

The higher sorption in the acidic subsoil is consistent with compound ionization and preferential retention of the organic cation over the neutral compound. Significant protonation of the compounds occurs in the Loring subsoil (Table IV) with the strongest base (acridine) being most ionized. When the protonated and neutral species coexist, site-specific sorption of the cation is preferred because of the large molar excess in negatively charged surface sites and the greater free-energy change arising from electrostatic over solvophobic interaction (27). While direct comparisons between Freundlich constants $\left(K_{\mathrm{F}}\right.$, Table II) and estimated $K_{\mathrm{p}}$ values (Table IV) based on organic

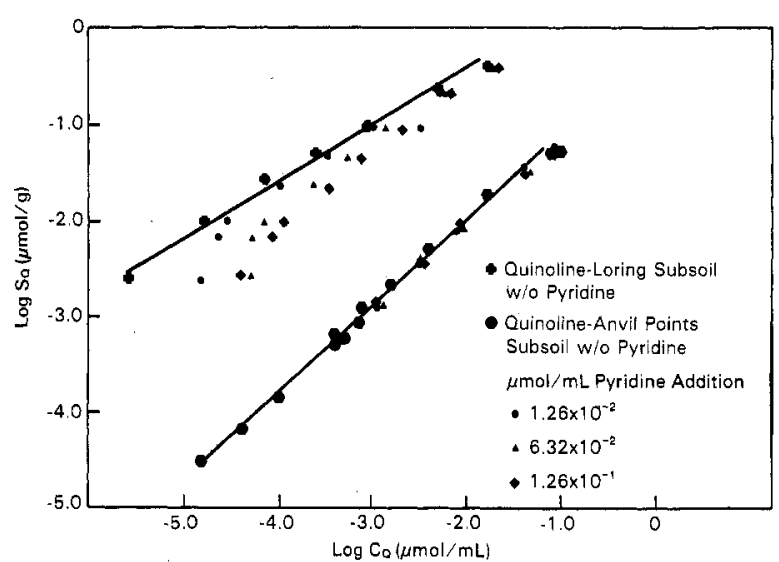

Figure 2. Sorption of quinoline at 1:5 solid-to-solution ratio with and without pyridine.

carbon content are not possible because of isotherm nonlinearity, the estimated $K_{\mathrm{p}}$ values on both subsoils are too small to account for the observed sorption behavior. Even in the absence of ionic interactions of the organic cation, carbon-referenced sorption cannot account for the observed sorption because of the low carbon content of these subsurface materials. The clay mineral to organic carbon ratios (cm/oc, Table I) exceed the empirical threshold where mineral contributions to hydrophobic sorption have been observed to begin $(24,25)$.

Ion exchange is hypothesized to dominate the sorption process in the acidic subsoil, and conditional equilibrium constants $\left(K_{\mathrm{v}}\right.$, Table IV) were estimated for the assumed exchange reaction

$$
\mathrm{CaX}_{2}+2 \mathrm{BH}^{+} \rightleftharpoons 2 \mathrm{BHX}+\mathrm{Ca}^{2+}
$$

where $\mathrm{X}$ represents 1 equiv of surface charge. It was assumed that all adsorbed base in the acidic subsoil was present as the protonated species and that the CEC represented the concentration of reactive surface sites. Selectivity for all compounds over $\mathrm{Ca}^{2+}$ is high at low aqueous concentration, with variable effects noted as organic concentrations increase. The large range in selectivity coefficients for quinoline and pyridine reflects nonideal exchange arising from the contribution of multiple sorbents of varying selectivity (28). Greater selectivity with ring number can be ascribed to van der Waals forces (29) between the sorbate and the associated adsorbent surface. Similar behavior has been noted for a series of alkylammonium cations of increasing carbon number (30). In addition, increasing ring number allows dispersion of positive charge over a larger molecular surface area, which enhances surface protonation (31) and facilitates Coulombic attraction to delocalized regions of surface charge.

Binary Solute Sorption. (A) Quinoline/Pyridine. Quinoline adsorption is reduced by pyridine in the acidic subsoil but remains unaffected in the basic subsoil (Figure 2 ). In the acidic subsoil the competitive effect increases

Table IV. Ionization Fraction and Estimated Binding Constants

\begin{tabular}{lcc} 
& \multicolumn{2}{c}{$Q^{a}$} \\
\cline { 2 - 3 } compd & Loring & Anvil Points \\
pyridine & 0.933 & 0.005 \\
quinoline & 0.866 & 0.002 \\
acridine & 0.974 & 0.013
\end{tabular}

\begin{tabular}{lc}
\multicolumn{2}{c}{ estimated $K_{\mathrm{p}}, \mathrm{mL} / \mathrm{g}^{b}$} \\
\hline Loring & Anvil Points \\
0.012 & 0.027 \\
0.127 & 3.07 \\
2.90 & 7.02
\end{tabular}

\begin{tabular}{cc}
\multicolumn{2}{c}{$\log K_{\mathrm{v}}{ }^{\mathrm{c}}$} \\
\hline $\operatorname{low} C_{\mathrm{e}}$ & high $C_{\mathrm{e}}$ \\
0.46 & -0.52 \\
3.67 & 0.58 \\
4.58 & 5.24
\end{tabular}

${ }^{a} Q=[\mathrm{BH}] /\left(\left[\mathrm{BH}^{+}\right]+[\mathrm{B}]\right)=1 /\left(1+K_{\mathrm{a}} \gamma^{+} /\left[\mathrm{H}^{+}\right]\right)$, where $\gamma^{+}(0.849)$ was obtained from the Davies equation with $I=0.03 \mathrm{M}$. ${ }^{b} \log K_{0}=\log$

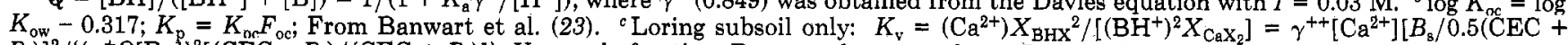
$\left.\left.B_{\mathrm{s}}\right)\right]^{2} /\left\{\left(\gamma^{+} Q\left[\mathrm{~B}_{\mathrm{T}}\right]\right)^{2}\left[\left(\mathrm{CEC}-B_{\mathrm{s}}\right) /\left(\mathrm{CEC}+B_{\mathrm{s}}\right)\right]\right\} ; X=$ mole fraction, $\mathrm{B}_{\mathrm{T}}=$ total aqueous base, $B_{\mathrm{s}}=$ total sorbed base, $\left(\mathrm{BH}^{+}\right)=$activity of $\mathrm{BH}^{+}$, $\left(\mathrm{Ca}^{2+}\right)=$ activity of $\mathrm{Ca}^{2+}$, and $\mathrm{CEC}=$ cation exchange capacity. 


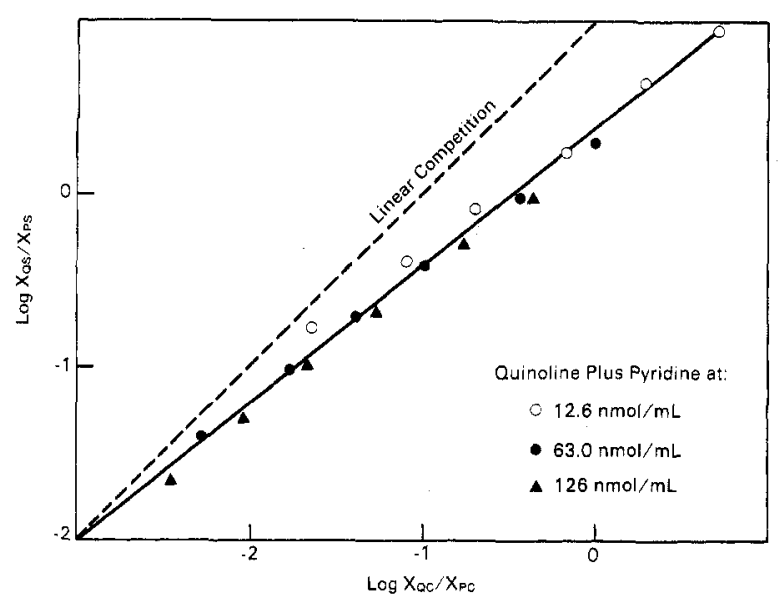

Figure 3. Mole fraction of quinoline to pyridine on surface $\left(x_{\mathrm{QS}} / X_{\mathrm{PS}}\right)$ vs. that in solution $\left(X_{\mathrm{OC}} / X_{\mathrm{PC}}\right)$ for quinoline/pyridine binary solute sorption on Loring subsoil.

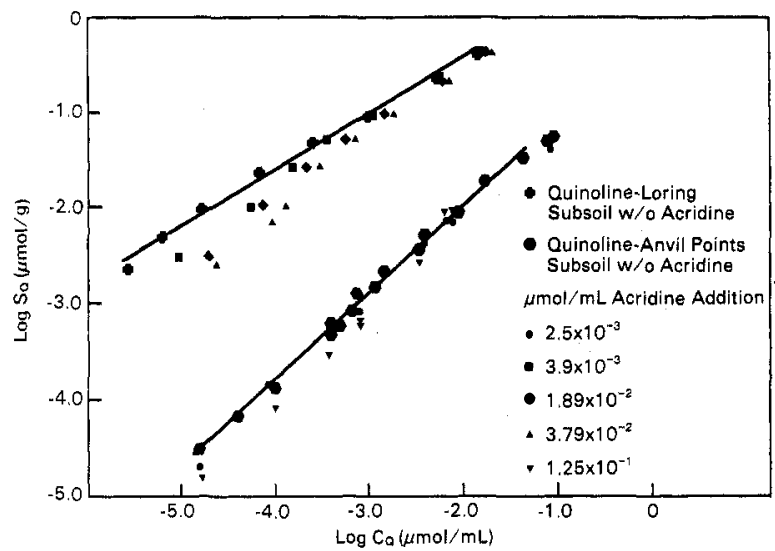

Figure 4. Sorption of quinoline on two subsolls at 1:5 solid-to-solution ratio with and without acridine.

with pyridine concentration, which displaces the isotherm downward and to the right. In general, curvilinear sorption behavior for quinoline increases in the binary solute system. Slight competition occurs when quinoline and pyridine are present at a comparable initial molar concentration; however, the greatest effect occurs when the initial molar ratio is lowest [quinoline $(\mathrm{M})$ /pyridine $(\mathrm{M})=0.04$ ] At this ratio, competition with pyridine may increase quinoline equilibrium solution concentrations by up to 2 orders of magnitude over that observed in the absence of the binary solute.

In the binary solute system with quinoline, pyridine sorption (data not shown) is decreased, relative to its single solute behavior, in a fashion analogous to quinoline. The ratio of the mole fractions of quinoline to pyridine at equilibrium in solution $\left(X_{\mathrm{QC}} / X_{\mathrm{PC}}\right)$ is plotted vs. that on the solid $\left(X_{\mathrm{QS}} / X_{\mathrm{PS}}\right)$ in Figure 3. Quinoline is preferred on the surface over much of the concentration range, but this preference decreases with increasing quinoline concentration and $X_{\mathrm{QC}} / X_{\mathrm{PC}}$. This decreasing preference reflects the nonlinear sorption behavior of the two individual solutes and their nonequivalent values of the Freundlich exponential term. The quinoline preference is consistent with the observation that pyridine sorption exceeds that of quinoline at higher solution concentrations (greater than $10^{-1.5} \mu \mathrm{mol} / \mathrm{mL}$ ), while the inverse holds at lower concentrations (Figure 1). Solutes exhibiting nonequal but linear sorption behavior would exhibit a slope of unity on this plot, and a change in the solution mole fraction ratio would result in an equivalent change in the surface mole fraction ratio.

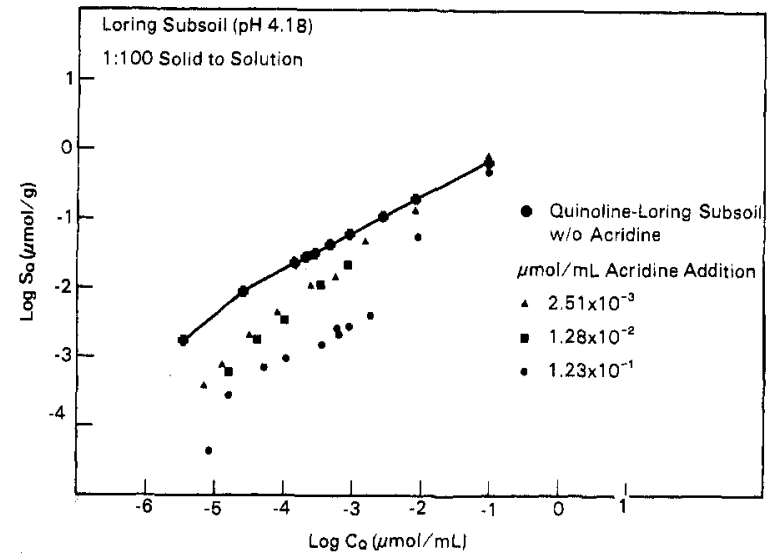

Flgure 5. Sorption of quinoline on the Loring subsoll at 1:100 solidto-solution ratio with and without quinoline.

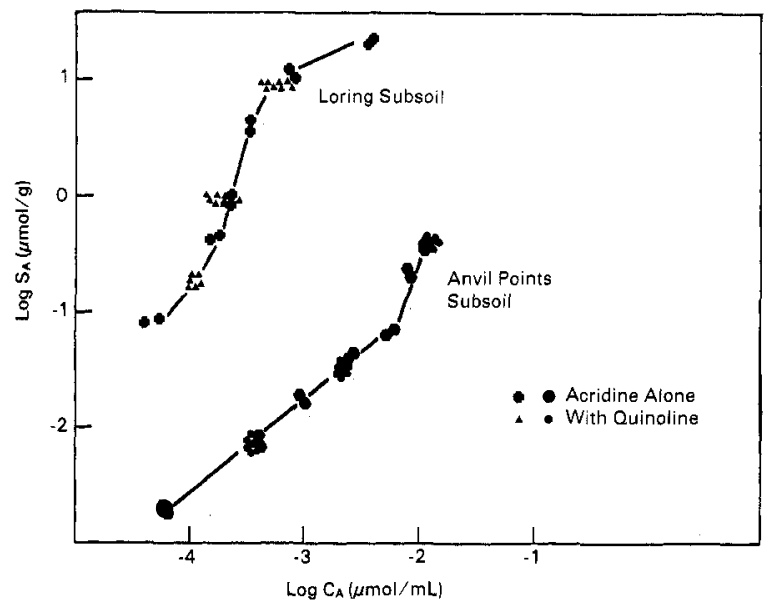

Figure 6. Acridine sorption on Loring and Anvil Points subsoils at 1:100 solid-to-solution ratio with and without quinoline.

(B) Quinoline/Acridine. Acridine depresses quinoline sorption in the acidic subsoil at a 1:5 solid-to-solution ratio (Figure 4). Competition in the basic subsoil is suggested, but the difference in adsorption is not statistically significant. In the acidic subsoil, increasing the acridine concentration results in reduced quinoline sorption. The reduction is similar to that observed for competition with pyridine, although it occurs at lower initial molar concentrations of the competing compound. A similar binary experiment using different acridine concentrations was performed for the acidic subsoil at a low solid-to-solution ratio (1:100). This experiment was performed to enable HPLC analysis of acridine equilibrium solution concentrations that were below detection in the 1:5 ratio experiment. As observed in the 1:5 ratio experiments, increasing the molar concentrations of acridine produces a progressive reduction in quinoline sorption (Figure 5) that is greatest at low quinoline and high acridine concentration. Compared to the 1:5 ratio experiment, the influence of acridine is more pronounced over the quinoline equilibrium concentration range of $10^{-4}-10^{-2.5} \mu \mathrm{mol} / \mathrm{mL}$, particularly for the highest acridine concentration. This enhanced competition reflects a smaller percent change in the initial concentration ratio of the two solutes during sorption. Competition nearly vanishes when quinoline equilibrium concentrations exceed $10^{-2} \mu \mathrm{mol} / \mathrm{mL}$

In direct contrast to pyridine, acridine sorption is little influenced by the presence of quinoline. High-performance liquid chromatography analysis of acridine concentrations in the binary experiments indicates that acridine sorption is well described by the single solute isotherms (Figure 6), 
Table V. Average Percent Error (APE) for Quinoline between Experimental Data and IAS Predictions for Sorption in Binary Solute Mixtures

\begin{tabular}{|c|c|c|c|c|c|c|c|}
\hline \multirow[b]{2}{*}{ cosolute } & \multirow[b]{2}{*}{ soil } & \multirow[b]{2}{*}{ ratio } & \multicolumn{2}{|c|}{ initial concn, $\mu \mathrm{mol} / \mathrm{mL}$} & \multirow[b]{2}{*}{$N^{a}$} & \multicolumn{2}{|c|}{$\mathrm{APE}^{b}$} \\
\hline & & & quinoline & cosolute & & $\mathrm{Ce}$ & $\mathrm{S}$ \\
\hline pyridine & Loring & $1: 5$ & $\begin{array}{l}5.27 \times 10^{-2} \text { to } 1.00 \times 10^{-1} \\
5.27 \times 10^{-2} \text { to } 1.00 \times 10^{-1} \\
5.27 \times 10^{-2} \text { to } 1.00 \times 10^{-1}\end{array}$ & $\begin{array}{l}1.26 \times 10^{-2} \text { to } 1.24 \times 10^{-2} \\
6.3 \times 10^{-2} \text { to } 6.2 \times 10^{-2} \\
1.26 \times 10^{-1} \text { to } 1.24 \times 10^{-1}\end{array}$ & $\begin{array}{l}8 \\
8 \\
8\end{array}$ & $\begin{array}{l}79.2 \\
44.7 \\
39.8\end{array}$ & $\begin{array}{r}12.4 \\
2.45 \\
2.78\end{array}$ \\
\hline acridine & Loring & $1: 100$ & $\begin{array}{l}1.04 \times 10^{-5} \text { to } 9.49 \times 10^{-2} \\
2.09 \times 10^{-5} \text { to } 4.29 \times 10^{-4} \\
1.05 \times 10^{-5} \text { to } 9.50 \times 10^{-2}\end{array}$ & $\begin{array}{l}1.29 \times 10^{-1} \text { to } 1.25 \times 10^{-1} \\
1.29 \times 10^{-2} \\
5.57 \times 10^{-3} \text { to } 2.5 \times 10^{-3}\end{array}$ & $\begin{array}{r}11 \\
4 \\
11\end{array}$ & $\begin{array}{l}3.14 \\
10.4 \\
18.6\end{array}$ & $\begin{array}{l}50.5 \\
25.3 \\
70.2\end{array}$ \\
\hline acridine & Anvil Points & $1: 5$ & $\begin{array}{l}2.09 \times 10^{-5} \text { to } 9.50 \times 10^{-2} \\
2.09 \times 10^{-5} \text { to } 9.50 \times 10^{-2}\end{array}$ & $\begin{array}{l}1.25 \times 10^{-1} \\
2.5 \times 10^{-3}\end{array}$ & $\begin{array}{r}7 \\
7\end{array}$ & $\begin{array}{l}3.6 \\
6.06\end{array}$ & $\begin{array}{l}20.6 \\
28.6\end{array}$ \\
\hline
\end{tabular}

${ }^{a} N=$ number of replicate data points. ${ }^{b} \mathrm{APE}=(100 / N) \sum\left(\mathrm{X}_{\text {obsd }}-\mathrm{X}_{\text {pred }}\right) / \mathrm{X}_{\text {obsd }}$, where $\mathrm{X}$ is $\mathrm{Ce}$ or $\mathrm{S}$ and $N=$ number of observations. Average percent error presented for quinoline only.

Table VI. Average Percent Error (APE) between Experimental Data and IAS Predictions for Single Solute Adsorption

\begin{tabular}{|c|c|c|c|c|c|c|}
\hline \multirow[b]{2}{*}{ compd } & \multirow[b]{2}{*}{ soil } & \multirow[b]{2}{*}{ ratio } & \multirow[b]{2}{*}{ initial concn range, $\mu \mathrm{mol} / \mathrm{mL}$} & \multirow[b]{2}{*}{$N$} & \multicolumn{2}{|c|}{ APE } \\
\hline & & & & & $\mathrm{Ce}$ & $\mathbf{S}$ \\
\hline \multirow[t]{3}{*}{ quinoline } & Loring & $1: 5$ & $5.16 \times 10^{-4}$ to $1.00 \times 10^{-1}$ & 8 & 17.6 & 0.8 \\
\hline & Loring & $1: 100$ & $3.62 \times 10^{-6}$ to $8.77 \times 10^{-2}$ & 8 & 10.5 & 11.6 \\
\hline & Anvil Points & $1: 5$ & $5.16 \times 10^{-4}$ to $1.00 \times 10^{-1}$ & 8 & 2.15 & 7.85 \\
\hline \multirow[t]{2}{*}{ pyridine } & Loring & $1: 5$ & $2.62 \times 10^{-2}$ to 1.24 & 6 & 8.04 & 4.96 \\
\hline & Anvil Points & $1: 5$ & $2.49 \times 10^{-2}$ to 1.24 & 5 & 2.28 & 85.6 \\
\hline \multirow[t]{2}{*}{ acridine } & Loring & $1: 100$ & $9.15 \times 10^{-4}$ to $2.29 \times 10^{-1}$ & 6 & 51.3 & 1.77 \\
\hline & Anvil Points & $1: 5$ & $3.66 \times 10^{-4}$ to $9.15 \times 10^{-2}$ & 7 & 30.6 & 7.0 \\
\hline
\end{tabular}

in spite of the presence of a reactive cosolute. At higher acridine and quinoline concentrations in the more adsorbent acidic subsoil, there was indication that acridine sorption was slightly enhanced by the presence of quinoline.

Descriptive Relationships. A simplified version of the ideal adsorbed solution (IAS) model described by Crittenden et al. (9) was used to simulate the binary sorption experiments. In the simplified version, single solute isotherm equations are used in the IAS framework to approximate the relationship of surface spreading pressure $(\pi)$ to surface loading $(S)$ (31). Like Crittenden et al. (9), we have used single solute Freundlich isotherms, even though these isotherms do not reduce to Henry's law at vanishing aqueous concentrations. The numerical model predicts the adsorbed concentration of solute $i\left(S_{i}\right)$ at equilibrium on the basis of the initial concentrations of the binary solutes $\left(C_{0 i}\right)$ and their respective single solute Freundlich isotherm parameters, $K_{\mathrm{F} i}$ and $N_{i}$. The aqueous equilibrium concentration $\left(C_{\mathrm{e} i}\right)$ is subsequently calculated with this predicted $S_{i}$ value and a mass balance expression for the sorption experiment:

$$
C_{\mathrm{e} i}=C_{0 i}-\frac{M S_{i}}{V}
$$

where $M$ is the sorbent mass and $V$ is solution volume.

In most cases, IAS calculations based on single solute Freundlich constants in Table II were in qualitative agreement with the experimental data (Figure 7). The simulations successfully predict the reduction in quinoline sorption that occurs in the presence of acridine and pyridine in the acidic subsoil (Figure 7a,b) and substantiate the small competitive effect induced by acridine in the basic subsoil (Figure 7c).

Average percent error (APE) in the sorbed $(S)$ and aqueous equilibrium concentration $\left(C_{\mathrm{e}}\right)$ varied between solute pairs, ranging from approximately $2.5 \%$ to $80 \%$ (Table V). Model calculations generally predicted more competition than was observed. This error in the IAS calculations stems, in part, from propagation of error from the single solute isotherms, which exhibit curvilinearity on a log-log plot (see Figure 1). The APE of single solute IAS calculations (Table VI) reflects this curvilinearity. As suggested by Crittenden et al. (11), the accuracy of these simulations may be improved by using more complex isotherm equations that give closer fit to the single solute data. Additionally, the relative precision of predicted $S$ vs. $C_{e}$ concentrations in the binary systems was dependent on the magnitude of sorption and the solid-to-solution ratio. The closest agreement between predicted and observed equilibrium solution concentrations occurred when the change in aqueous concentration was small (i.e., 20-40\%) during sorption (Loring 1:100, Anvil Points 1:5; see Table V). When the percent change is large (i.e., 70-90\%, Loring 1:5), APE in the adsorbed concentration is lowest. For a given subsurface material, APE in the predicted equilibrium solution concentration $\left(C_{\mathrm{e}}\right)$ appears to increase as the solid-to-solution ratio increases toward that of the natural subsurface environments.

\section{Conclusions}

Binary solute experiments demonstrate that competition occurs between NHC when the adsorbing compounds are partly ionized and sorbed via ion exchange. In contrast, NHC sorb independently when the neutral species predominates in solution. The absence of solute competition has been noted previously for nonionic compounds sorbing nonspecifically in soil (8). Competition in the acid subsoil is consistent with mass action between the binary solutes for a limited population of surface sites that bind all three NHC. The extent of competition reflects the sorption strength of the individual solutes, which is inversely proportional to aqueous solubility of the compounds.

These static equilibrium experiments suggest that solute competition within mixtures may enhance the mobility of nitrogen heterocycle compounds in groundwater, particularly where the groundwater $\mathrm{pH}$ allows partial or full compound protonation. This implication must be viewed in the context of the subsurface environment where sorption occurs from a mobile and dynamic fluid phase. Acridine was shown to induce the greatest depression in the sorption of quinoline, the reference compound. How- 

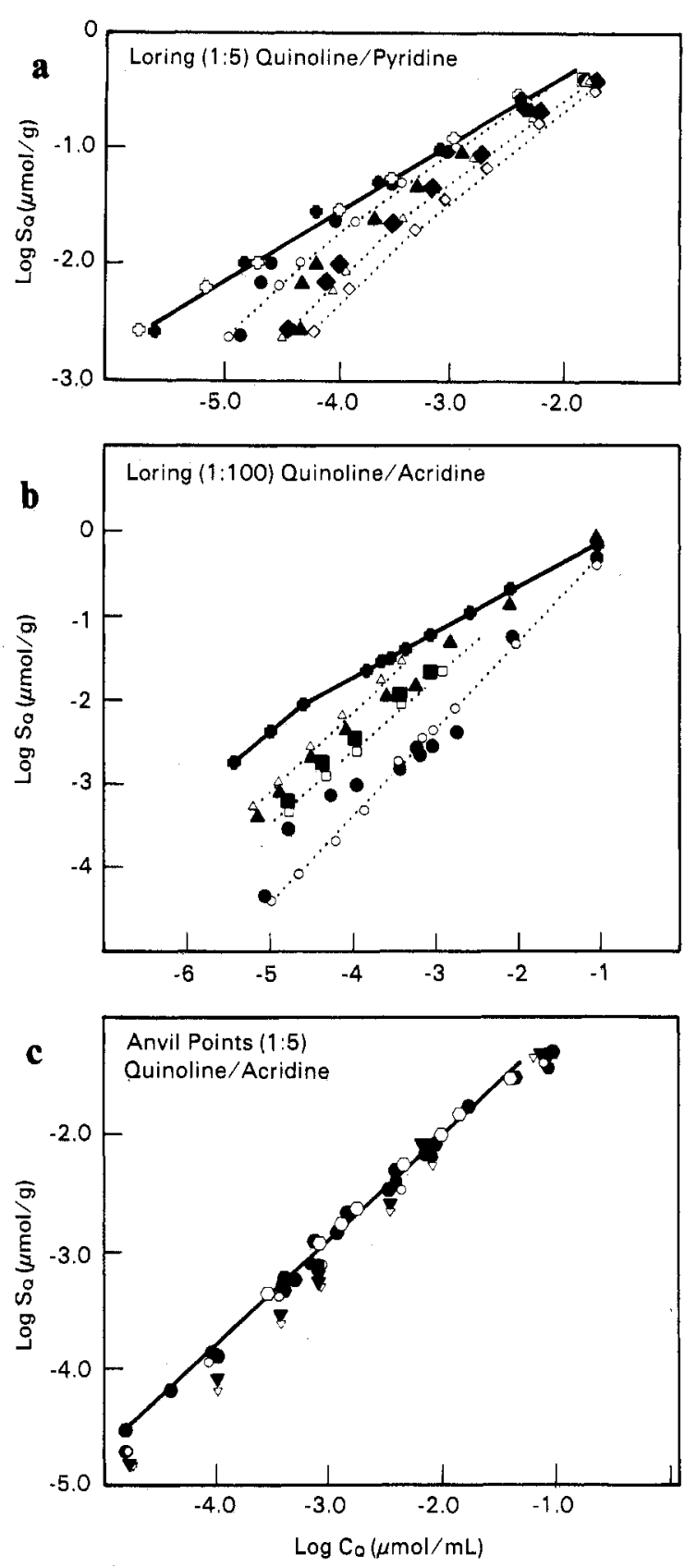

Figure 7. IAS simulations of binary solute experiments. Closed symbols are data points. Open symbols are model predictions. (a) 1:5 quinoline/pyridine on Loring subsoil; (b) 1:100 quinoline/acridine on Loring subsoil; (c) 1:5 quinoline/acrldine on Anvil Points subsoil.

ever, if these contaminants were released below ground from a single point source, the distance over which quinoline/acridine competition would occur could be minimal because of the strong sorption of acridine. In contrast, quinoline and pyridine would compete over mugh longer transport distances because of their similar sorption intensities. Because of differential compound mobility in a dynamic fluid, the magnitude of the competitive effect will depend on the sorption strength of the individual compounds and the timing of their release to the subsurface. We suggest that competitive interactions may occur over longer transport distances for constant source contaminant release situations than for pulse release events.

\section{Acknowledgments}

We have benefited through technical discussions with P. S. C. Rao of the University of Florida and extend our appreciation to L. J. Felice and R. L. Schmidt, who provided technical assistance in the earlier stages of the experimental work.

Registry No. C, 7440-44-0; pyridine, 110-86-1; acridine, 260-94-6; quinoline, 91-22-5.

\section{Literature Cited}

(1) Murali, V.; Aylmore, L. A. G. Soil Sci. 1983, 136, 279-290.

(2) Hendrickson, L. L.; Corey, R. B. Soil Sci. 1981, 131, 163-171.

(3) Goldberg, S. Soil Sci. Soc. Am. J. 1985, 49, 851-856.

(4) Zachara, J. M.; Girvin, D. C.; Schmidt, R. L.; Resch, C. T., submitted for publication in Environ. Sci. Technol.

(5) Weed, S. B.; Weber, J. B. Am. Mineral. 1968, 53, 478-490.

(6) Philen, O. D., Jr.; Weed, S. B.; Weber, J. B. Soil Sci. Soc. Am. Proc. 1970, 34, 527-531.

(7) Nkedi-Kizza, P.; Rao, P. S. C.; Sherwood, J. M.; Delfino, J. J. "Sorption of Organic Chemicals by Soils from Multi-Sorbate Mixtures"; American Society of Agronomy 76th Annual Meeting, Las Vegas, NV, Nov 25-30, 1984.

(8) Chiou, C. T.; Porter, P. E.; Schmedding, D. W. Environ. Sci. Technol. 1983, 17, 227-231.

(9) Crittenden, J. C.; Luft, P.; Hand, D. W.; Oravitz, J. L.; Loper, S. W.; Ari, M. Environ. Sci. Technol. 1985, 19, 1037-1043.

(10) Jossens, L.; Prausnitz, J. M.; Fritz, W.; Schlunder, E. V.; Myers, A. L. Chem. Eng. Sci. 1978, 33, 1097-1106.

(11) Murin, C. J.; Snoeyink, V. L. Environ. Sci. Technol. 1979, $13,305-311$.

(12) Fritz, W.; Schlunder, E. V. Chem. Eng. Sci. 1981, 36, $721-730$.

(13) Muller, G.; Radke, C. J.; Prausnitz, J. M. J. Colloid Interface Sci. 1985, 103, 484-492.

(14) Sheindorf, C.; Rebhun, M.; Sheintuch, M. J. Colloid Interface Sci. 1981, 79, 136-142.

(15) Sheindorf, C.; Rebhun, M.; Sheintuch, M. Water Res. 1982, 16, 357-362.

(16) Radke, C. J.; Prausnitz, J. M. AIChE J. 1972, 18, 761 768.

(17) Muller, G.; Radke, C. J.; Prausnitz, J. M. J. Colloid Interface Sci. 1985, 103, 466-483.

(18) Belfort, G. Environ. Sci. Technol. 1979, 13, 939-945.

(19) Zachara, J. M.; Felice, L. J.; Riley, R. G.; Harrison, F. L.; Mallon, B. The Selection of Organic Chemicals for Subsurface Transport Research; U.S. Department of Energy: Washington, DC, 1984; DOE/ER-0217.

(20) Zachara, J. M.; Ainsworth, C. C.; Felice, L. J.; Resch, C. T. Environ. Sci. Technol. 1986, 20,620-627.

(21) Soil Conservation Service "Soil Survey of Daviess and Hancock Counties, Kentucky"; U.S. Department of Agriculture: Washington, DC, 1974.

(22) Koskinen, W. C.; Cheng, H. H. Soil Sci. Soc. Am. J. 1982, $46,256-259$

(23) Banwart, W. L.; Hassett, J. J.; Wood, S. G.; Means, J. C. Soil Sci. 1982, 133, 42-47.

(24) Means, J. C.; Wood, S. G.; Hassett, J. J.; Banwart, W. L. Environ. Sci. Technol. 1982, 16, 93-98.

(25) Karickhoff, S. W. J. Hydraul. Eng. 1984, 110, 707-735.

(26) Rao, P. S. C.; Hornsby, A. G.; Kilcrease, D. P.; Nkedi-Kizza, P. J. Environ. Qual. 1985, 14,376-383.

(27) Horvath, C.; Melander, R. W.; Molnar, W. J. Chromatogr. $1976,125,129-156$.

(28) Sposito, G. The Thermodynamics of Soil Solutions; Oxford University Press: New York, 1981.

(29) Hendricks, S. B. J. Phys. Chem. 1941, 45, 65-81.

(30) Cowan, C. T.; White, D. Trans. Faraday Soc. 1958, 54, 691-697.

(31) Karickhoff, S. W.; Bailey, G. W. Clays Clay Miner. 1976, $24,170-176$

Received for review May 7, 1986. Accepted November 14, 1986 This research was sponsored by the Ecological Research Division, Office of Health and Environmental Research, U.S. Department of Energy, under Contract DE-AC06-76RLO 1830. 